\title{
Multivariate statistical analysis of the polyphenols content for the discrimination of honey produced in Sicily (Southern Italy)
}

\author{
Gianluigi Maria Lo Dico ${ }^{\mathrm{a},}$, Alessandro Ulrici ${ }^{\mathrm{b}}$, Andrea Pulvirenti ${ }^{\mathrm{b}}$, Gaetano Cammilleri ${ }^{\mathrm{a}}$, Andrea Macaluso ${ }^{\mathrm{a}}$, \\ Antonio Vella $^{\text {a }}$, Vita Giaccone ${ }^{a}$, Giovanni Lo Cascio ${ }^{a}$, Stefania Graci ${ }^{a}$, Maria Scuto ${ }^{c}$, Angela Trovato Salinaro ${ }^{c}$, \\ Vittorio Calabrese ${ }^{c}$, Rea Lo Dico ${ }^{d}$, Vincenzo Ferrantelli ${ }^{\text {a }}$ \\ a Istituto Zooprofilattico Sperimentale della Sicilia “A. Mirri”, Via Gino Marinuzzi 3, 90129 Palermo, Italy \\ b Dipartimento di Scienze della Vita, Università degli studi di Modena e Reggio Emilia, Via Università 4, 41121 Modena, Italy \\ c Department of Biomedical and Biotechnological Sciences, School of Medicine, University of Catania, via Santa Sofia 89, 95123 Catania, Italy \\ ${ }^{\mathrm{d}}$ Service de Chirurgie Digestive et Cancérologique, Hôpital Lariboisière, Unitè INSERM U965 / CART, Paris 7 Diderot, 75010 Paris, France
}

\section{A R T I C L E I N F O}

Chemical compounds studied in this articles: Vanillic acid (PubChem CID: 8468) Syringic acid (PubChem CID: 10742) Trans-ferulic acid (PubChem CID: 445858) Myricetin (PubChem CID: 5281672) Naringenin (PubChem CID: 932) Pinocembrin (PubChem CID: 68071) Luteolin (PubChem CID: 5280445) Hesperidin (PubChem CID: 3594) Gallic acid (PubChem CID: 370) Caffeic acid (PubChem CID: 689043) Apigenin (PubChem CID: 5280443) Quercetin (PubChem CID: 5280343) Kaempferol (PubChem CID: 5280863) Catechin (PubChem CID: 107957) Epicatechin (PubChem CID: 182232) Chlorogenic acid (PubChem CID: 1794427)

Keywords:

Polyphenols

Nutraceutical

Liquid chromatography

High resolution mass spectrometry

Multivariate analysis

\begin{abstract}
A B S T R A C T
The polyphenols content of 105 honey samples produced by black honeybees (Apis Mellifera ssp. Sicula) and common honeybees (Apis mellifera ssp. Ligustica) from Western Sicily (Southern Italy) was examined using TurboFlow ${ }^{\mathrm{TM}}$ liquid chromatography Orbitrap ${ }^{\mathrm{TM}}$ high-resolution mass spectrometry. The results showed very high kaempferol and quercetin contents, with average values higher than what was reported in literature ( $3967.9 \pm 2184.16$ and $2206.1 \pm 1666.4 \mu \mathrm{g} \mathrm{kg}^{-1}$ for kaempferol and quercetin, respectively). The honey samples produced by Apis Mellifera ssp. Sicula subspecies showed polyphenols content up to two times higher than Apis mellifera ssp. Ligustica. The Principal Component Analysis (PCA) model calculated on the polyphenols content showed a satisfactory separation of the honey samples in terms of honeybee subspecies and production area. The model proposed in this work shows the possibility to safeguard the authenticity of the honey produced in the various geographic areas of Sicily.
\end{abstract}

\section{Introduction}

During the last decades, food characterization becomes a challenging topic because it includes both authenticity and geographical origin determination (Mallamace et al., 2014; Pantano et al., 2016). Honey is a complex natural mixture that contains various nutrients and bioactive compounds, such as polyphenols, which are considered the major for wide range of biochemical activities of honey (Bogdanov et al., 2008; Cicero et al., 2017; Tenore et al., 2012). There is a significant correlation between antioxidant activity, polyphenol content, and inhibition of human serum lipoprotein oxidation in vitro (Gheldof et al., 2002; Pérez-Gregorio et al., 2014; Perez-Gregorio and Simal-Gandara, 2017). Most of the polyphenols present in honey are flavonoids (hesperidin, quercetin, naringenin, pinocembrin, luteolin, kaempferol, rutin, apigenin, and myricetin), phenolic acids, phenolic acid derivatives (e.g., gallic acid, chlorogenic acid, vanillic acid,

\footnotetext{
* Corresponding author.

Email address: gigilodico@gmail.com (G.M. Lo Dico)
} 
caffeic acid, syringic acid, ferulic acid, and ellagic acid), and flavones, having neuroprotective, anti-inflammatory, chemo-protective anticarcinogenic properties, due to their antioxidative and anti-anxiety activity (Filomeni et al., 2012; Li and Pu, 2011; Ban et al., 2008; Luo et al., 2012; Seeram et al., 2005; Uzar et al., 2012; Ban et al., 2008; Mandel et al., 2005).

The classification and quantification of polyphenols and other components are essential in determining the effects of environment on honey and other food types characterization, since these compounds varies according to the climate and other environmental conditions of the production area (Rodríguez-Delgado et al., 2002; Tenore et al., 2012). Even the honeybee species employed for production could contribute to differences in the chemical composition of honey. The Sicilian black honeybee (Apis mellifera ssp. sicula) is a subspecies of a more common honeybee (Apis mellifera ssp. ligustica), from which it differs for various features (Tenore et al., 2012). In the phylogeographical study of honeybee populations, especially in Mediterranean areas, human influences must be accounted for Franck et al. (2000). For this reason, various genetic characteristics derived from the African and/or Oriental branches could have been incorporated into Sicilian honeybee populations (Ruttner, 2013).

The Sicilian black honeybees differ from Apis mellifera ssp. ligustica in regard to color, wing dimensions, and resistance to various physical and biological parameters (Tenore et al., 2012). The Sicilian black honeybees tolerate temperatures above $40^{\circ} \mathrm{C}$, whereas other subspecies are not able to produce honey at such temperatures. In addition, they have a great pollination ability, thus ensuring the survival of many species of fruits and vegetables (Tenore et al., 2012). At present, Sicilian honeys are not guaranteed by EU quality labels (PDOs and PGIs), probably due to the lack of data regarding their physical and chemical properties that do not allow to have comprehensive comparison. Multivariate analysis has usually been employed for food quality assessment as well as for honey and other products (Kallithraka et al., 2001; Mallamace et al., 2014; Rodríguez-Delgado et al., 2002). Among the many multivariate analysis methods available, Principal Component Analysis (PCA) is the most frequently used for exploratory data analysis. In fact, PCA allows to achieve a significant reduction of data dimensionality, by estimating the correlation structure of the variables and defining a restricted number of variables (Principal Components, PCs) that allow to describe the statistically significant variability within the data, with a minimum loss of information.

In this work, 105 honey samples from Sicily (Southern Italy) were examined to evaluate the major classes of polyphenols using an automated TurboFlow ${ }^{\mathrm{TM}}-$ liquid chromatography Orbitrap ${ }^{\mathrm{TM}}$ high-resolution mass spectrometry method (LC-ESI-Orbitrap ${ }^{\mathrm{TM}}-\mathrm{MS} / \mathrm{MS}$ ). Then, PCA was used to compare the honey varieties produced by Sicilian black bees (Apis Mellifera ssp. Sicula) with those produced by common bees (Apis mellifera ssp. Ligustica), based on their polyphenols content. Furthermore, PCA was also used to compare the honey varieties based on their production areas.

\section{Material And Methods}

\subsection{Chemicals, standards, and reagents}

All chemicals and reagents were either analytical-reagent or HPLC grade. Ultrapure deionized water, with a resistivity of $18.2 \mathrm{M} \Omega \mathrm{cm}$, was obtained from a Milli- ${ }^{\circledR}$ Integral water purification system with a Q-pod purchased from Millipore (Bedford, MA, USA). Acetic acid, acetonitrile, and 2-propanol were purchased from VWR International S.r.l. (Milan, Italy); hydrochloric acid and sodium hydroxide were purchased from Carlo Erba (Milan, Italy). HPLC gradient grade methanol was obtained from Merck (Darmstadt, Germany). Standard solutions of vanillic acid, syringic acid, trans-ferulic acid, myricetin, naringenin, pinocembrin, luteolin, and hesperidin were purchased from Extrasynthese (Genay Cedex, France); gallic acid, caffeic acid, apigenin, quercetin, kaempferol, catechin, and epicatechin were purchased from Sigma-Aldrich S.r.l. (Milan, Italy); chlorogenic acid was purchased from HWI Analytik GmbH (Rülzheim, Germany). The standards so- lutions were obtained by adding $10 \mathrm{mg}$ of the single powder standards (purity $>99.9 \%$ ) to $10 \mathrm{~mL}$ of methanol (except for Apigenin and Kaempferol dissolved in aqueous solution at $\mathrm{pH}>8$ ) in order to obtain a concentration of $1000 \mathrm{mgL}^{-1}$.

\subsection{Instrumentation}

The mixture of polyphenols $\left(1 \mathrm{mg} \mathrm{L}^{-1}\right)$ was determined using a Transcen II System with Multi-channel and TurboFlow ${ }^{\mathrm{TM}}$ Technology (Dionex - Thermo Fisher Scientific, Waltham, MA, USA) comprised of a low-pressure mixing quaternary pump for online extraction (loading pump), high-pressure mixing quaternary pump for analytical separation (eluting pump), and three-valve switching device unit with a six-port valve and $100 \mu \mathrm{L}$ loop. The samples were extracted and purified using a Cyclone P column $(50 \mathrm{~mm} \times 0.5 \mathrm{~m}, 60 \mu \mathrm{m}$ particle size, $60 \AA$ pore size, Thermo Fisher Scientific, Waltham, MA, USA); a Hypersil Gold $(2.1 \mathrm{~mm} \times 100 \mathrm{~mm}, 1.7 \mu \mathrm{m}$ particle size) column was employed as the analytical separation column. A Q-Exactive Plus Hybrid Quadrupole-Orbitrap $^{\mathrm{TM}}$ Mass Spectrometer (Thermo Fisher Scientific, Waltham, MA, USA) equipped with an HESI (Heated ElectroSpray Ionization) was used in positive and negative polarity modes. The GPS device used to detect the geographical sampling coordinates was a GPSMAP 62 STC (Garmin Ltd, Canton Schaffhausen, Switzerland). Temperature and humidity values were monitored with a data logger Smart Vue equipped with a PT100 probe (Thermo Fisher Scientific, Waltham, MA, USA).

\subsection{Honey samples collection and preparation}

A total of 105 multiflora honey samples were collected September to December 2015 by apiarists in different areas of Sicily (Southern Italy, Table 1). The samples were examined for geographical origin by melissopalynological analysis, according to the protocol of Ohe et al. (Ohe et al., 2004) by consulting the atlas of Ricciardelli d'Albore (1998). The samples were stored at controlled temperature and humidity conditions (about $25^{\circ} \mathrm{C}$ and $60 \%$ humidity) and protected from light and heat. The sample preparation was performed from January to April 2016 according to the method reported by Lopez-Gutiérrez N. et al. (López-Gutiérrez et al., 2014). Briefly, $5 \mathrm{~g}$ of the sample was weighed on an analytic balance and $50 \mathrm{~mL}$ of $30 \mathrm{mM}$ ammonium acetate $(\mathrm{pH} 5)$ / methanol mixture (50:50 V/V) was added to remove sugars and proteins, the best intensity for the compounds detected in the sample is

Table 1

Geographical coordinates and honeybee subspecies of the honey samples examined.

\begin{tabular}{|c|c|c|c|}
\hline $\begin{array}{l}\text { Site (number of } \\
\text { samples) }\end{array}$ & $\begin{array}{l}\text { Geographical } \\
\text { coordinates }\end{array}$ & Honeybee subspecies & $\begin{array}{l}\text { Macro- } \\
\text { Area }\end{array}$ \\
\hline Licata (2) & $\begin{array}{l}\left(37^{\circ} 06^{\prime} 29^{\prime \prime} \mathrm{N}, 13^{\circ} 55^{\prime}\right. \\
\left.55^{\prime \prime} \mathrm{E}\right)\end{array}$ & $\begin{array}{l}\text { Apis Mellifera ssp. } \\
\text { ligustica }\end{array}$ & 1 \\
\hline Ribera (2) & $\begin{array}{l}\left(37^{\circ} 30^{\prime} 32^{\prime} ’ \mathrm{~N}, 13^{\circ} 16^{\prime}\right. \\
\left.33^{\prime \prime} \mathrm{E}\right)\end{array}$ & & \\
\hline Raffadali (4) & $\begin{array}{l}\left(37^{\circ} 24^{\prime} 43^{\prime}, \mathrm{N}, 13^{\circ} 31^{\prime}\right. \\
\left.42^{\prime \prime} \mathrm{E}\right)\end{array}$ & & \\
\hline $\begin{array}{l}\text { S. Biagio Platani } \\
\text { (29) }\end{array}$ & $\begin{array}{l}\left(37^{\circ} 30^{\prime} 31^{\prime \prime} \mathrm{N}, 13^{\circ} 31^{\prime}\right. \\
\left.18^{\prime \prime} \mathrm{E}\right)\end{array}$ & & \\
\hline Sciacca (8) & $\begin{array}{l}\left(37^{\circ} 30^{\prime} 47^{\prime \prime} \mathrm{N}, 13^{\circ} 05^{\prime}\right. \\
\left.15^{\prime \prime} \mathrm{E}\right)\end{array}$ & & \\
\hline Naro (4) & $\begin{array}{l}\left(37^{\circ} 17^{\prime} 17^{\prime} ’ \mathrm{~N}, 13^{\circ} 47^{\prime}\right. \\
\left.58^{\prime \prime} \mathrm{E}\right)\end{array}$ & & \\
\hline Agrigento (15) & $\begin{array}{l}\left(37^{\circ} 18^{\prime} 48^{\prime \prime} \mathrm{N}, 13^{\circ} 35^{\prime}\right. \\
\left.19^{\prime \prime} \mathrm{E}\right)\end{array}$ & $\begin{array}{l}\text { Apis Mellifera ssp. } \\
\text { Sicula }\end{array}$ & \\
\hline Racalmuto (2) & $\begin{array}{l}\left(37^{\circ} 24^{\prime} 26^{\prime \prime} \mathrm{N}, 13^{\circ} 43^{\prime}\right. \\
\left.55^{\prime \prime} \mathrm{E}\right)\end{array}$ & & \\
\hline Lercara Friddi (3) & $\begin{array}{l}\left(37^{\circ} 45^{\prime} 11^{\prime \prime} \mathrm{N}, 13^{\circ} 35^{\prime}\right. \\
\left.40^{\prime \prime} \mathrm{E}\right)\end{array}$ & $\begin{array}{l}\text { Apis Mellifera ssp. } \\
\text { ligustica }\end{array}$ & 2 \\
\hline $\begin{array}{l}\text { Palazzo Adriano } \\
\text { (4) }\end{array}$ & $\begin{array}{l}\left(37^{\circ} 42^{\prime} 60^{\prime \prime} \mathrm{N}, 13^{\circ} 22^{\prime}\right. \\
\left.34^{\prime \prime} \mathrm{E}\right)\end{array}$ & $\begin{array}{l}\text { Apis Mellifera ssp. } \\
\text { Sicula }\end{array}$ & \\
\hline Bisacquino (14) & $\begin{array}{l}\left(37^{\circ} 42^{\prime} 26^{\prime}{ }^{\prime} \mathrm{N}, 13^{\circ} 15^{\prime}\right. \\
\left.05^{\prime \prime} \mathrm{E}\right)\end{array}$ & & \\
\hline $\begin{array}{l}\text { Contessa Entellina } \\
\text { (19) }\end{array}$ & $\begin{array}{l}\left(37^{\circ} 43^{\prime} 49^{\prime \prime} \mathrm{N}, 13^{\circ} 11^{\prime}\right. \\
\left.11^{\prime \prime} \mathrm{E}\right)\end{array}$ & & \\
\hline
\end{tabular}


obtained (López-Gutiérrez et al., 2014). The solution was filtered through a $\emptyset 0.20 \mu \mathrm{m}$ PTFA inert filter, to remove every impurities that could compromise the chromatographic analysis (Millipore, Bedford, MA, USA). The samples were transferred into an amber vial for HPLC analysis.

\subsection{Instrumental method}

The operation parameters were as follows: sheath gas flow rate, 35 (arbitrary units); aux gas flow rate, 10 (arbitrary units); spray voltage, $3.50 \mathrm{kV}$; capillary temperature, $300^{\circ} \mathrm{C}$; tube lens voltage, $55 \mathrm{~V}$; heater temperature, $305^{\circ} \mathrm{C}$; scan mode: full scan; scan range $(\mathrm{m} / \mathrm{z})$ 100-700; microscans, $1 \mathrm{~m} / z$; positive resolution: 70,000; FT automatic gain control (AGC) target: $3 \times 10^{6}$; maximum IT: $100 \mathrm{~ms}$; negative resolution: 35,000; automatic gain control (AGC) target: $1 \times 10^{6}$; maximum IT: $100 \mathrm{~ms}$. The chromatographic parameters were as follows: column temperature, $30^{\circ} \mathrm{C}$; sample temperature, $6^{\circ} \mathrm{C}$; flow rate, $0.2 \mathrm{~mL} \mathrm{~min}^{-1}$. The autosampler sample holder temperature was maintained at $7^{\circ} \mathrm{C}$. The mobile phase consisted of eluent A: $30 \mathrm{mM}$ ammonium acetate (pH 5), eluent B: methanol, eluent C: water (0.5\% formic acid), and eluent D: acetonitrile/acetone/2-propanol (4:3:3). Mobile phases A and B were used to optimize the chromatographic resolution; mobile phases $\mathrm{B}, \mathrm{C}$, and $\mathrm{D}$ were required for purification in TurboFlow ${ }^{\mathrm{TM}}$. The sample injection volume was $5 \mu \mathrm{L}$ with a $100 \mu \mathrm{L}$ injection syringe. The gradients for extraction, purification, and clean-up programs are presented in Table 2 . The total run time was $18 \mathrm{~min}$. The Data analysis was performed using Thermo Scientific XCalibur (Thermo Fisher Scientific, Waltham, MA, USA) version 4.0 software and Qual and Quant Browser.

\subsection{Method validation}

The method was validated according to EN ISO/IEC 17025:2005 (ISO/IEC 17025, 2005; Lo Dico et al., 2018). The limits of detection and quantification (LoDs and LoQs) were determined by the $3 \sigma$ and $10 \sigma$ approach. Fifteen blank samples spiked with $0.05 \mathrm{mg} / \mathrm{L}$ of all elements were analyzed. The calibration curve was constructed with 10 standard additions (0.01-0.05-0.1-0.2-0.5-1-2-5-10-50 $\mathrm{mgL}^{-1}$ ) and was checked using the $\mathrm{r}^{2}$ value. The linearity range was acceptable when $\mathrm{r}^{2}$ was greater than 0.999 in the peak areas vs. concentration. The recovery and limit of repeatability were evaluated at three different concentration levels $\left(0.1-1.0-10 \mathrm{mg} \mathrm{L}^{-1}\right)$. The level at $1.0 \mathrm{mgL}^{-1}$ was analyzed in another analytical session, by another operator, use $\emptyset 0.20 \mu \mathrm{m}$ PTFE filters and changing the reagents to calculating the reproducibility limit. The uncertainty associated with the preparation of the standard solutions was considered by the sum of the contributes: pipettes volume, scale and stock solutions. Then, the combined uncertainty (uc) was calculated as the square sum of the all contributes. The expanded measurement uncertainty $(U)$ is calculated with the formula:

$U=u_{c}(x)^{k}$

where $\mathrm{u}_{\mathrm{c}}$ is combined uncertainty, $\mathrm{k}$ is the coverage factor of 2 , considering a normal distribution of measurements with a $98 \%$ confidence level.

\subsection{Statistical analysis}

All the sampling sites were grouped into 2 macro-areas, corresponding to the provinces to which they belong (Agrigento and Palermo). All the results under the LOQ of the method were considered for the statistical analysis as half of the LOQ values, according to Helsel (Helsel, 2005). Before calculating the PCA model, four polyphenols with constant values (i.e., with concentrations always lower than the LOQ) were removed from the dataset, which then consisted in 14 polyphenols by 105 honey samples. All the variables were pretreated by autoscaling, considering that all the polyphenols bear potentially the same information content, regardless of their abundance. The PCA model was calculated using the software PLS-Toolbox ver. 8.5 (Eigenvector Research Inc., Wenatchee, WA, USA), running in the Matlab environment (ver. 9. 2, The Mathworks Inc., Natick, MA, USA).

\section{Results and Discussion}

The melissopalynological examination confirmed the geographical origin of all the honey samples examined being consistent with the flora of the sampling areas examined. None of the taxon examined has exceeded the relative frequency of $45 \%$ for the unifloral honey attribution. The list of 18 phenolic compounds identified by retention time and accurate mass of the parent ion are shown in Table 3. A molecular formula was generated using the accurate mass and by correspondence with the isotopic model of the identified phenolic compounds. The analytes were confirmed using mass/mass data and were compared to literature reports (López-Gutiérrez et al., 2014; Quifer-Rada et al., 2015; Vallverdú-Queralt et al., 2015). The extraction and purification step proposed in this work allowed us to separate the target compounds from macromolecules (López-Gutiérrez et al., 2014). Satisfactory linearity and recovery values were achieved during the validation of the method (Table 4). The validation allowed us to identify the uncertainty contributions to calculate the expanded uncertainty.

The mean values and standard deviation of the polyphenols sorted by sampling area and honeybee subspecies are shown in Table 5 and 6 . No detectable amounts of luteolin, ellagic acid, catechin and epicatechin were found in all the honey samples examined. The highest contents found corresponded to the flavonols group (kaempferol and quercetin), followed by pinocembrin and apigenin; kaempferol and quercetin levels corresponded to $69 \%$ of the total polyphenols content, with maximum values of $9599.23 \mu \mathrm{g} \mathrm{kg}-1$ and $8620.8 \mu \mathrm{g} \mathrm{kg}^{-1}$ for kaempferol and quercetin, respectively. The highest flavonols and pinocembrin contents were found in Sicilian black bee honey samples from Agrigento $(n=15)$ and Racalmuto $(\mathrm{n}=2)$. Among the hydroxybenzoic acids, vanillic and gallic acid showed the highest and lowest mean values $\left(142.5 \pm 105.6 \mu \mathrm{g} \mathrm{kg}-1\right.$ and $23.9 \pm 62.4 \mu \mathrm{g} \mathrm{kg}{ }^{-1}$, respectively). Vanillic acid contents were mostly found in samples from Palermo province (Bisacquino and Palazzo Adriano).

Of the three compounds examined in the hydroxycinnamic acids group (caffeic acid, chlorogenic acid and ferulic acid), caffeic acid presented the highest avereage content in all the analysed samples (394.1 $\pm 186.3 \mu \mathrm{g}$

Table 2

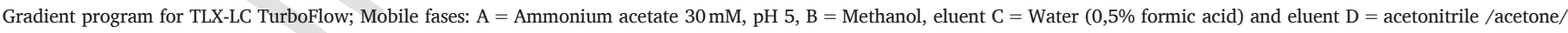
2-propanol (4:3:3).

\begin{tabular}{|c|c|c|c|c|c|c|c|c|c|c|c|c|}
\hline & Step & Loading Pump & & & & & & Cut-in Loop & Eluting Pump & & & \\
\hline & Start (min) & Flow (ml/min.) & Grad & $\mathrm{A}(\%)$ & B (\%) & $\mathrm{C}(\%)$ & $\mathrm{D}(\%)$ & Loop & Flow (ml/min.) & Grad & A (\%) & B (\%) \\
\hline Loading & 0.0 & 2.0 & Step & - & - & 100 & - & out & 0.2 & Step & 95 & 5 \\
\hline Transferring & 2.0 & 0.1 & Step & - & 100 & - & - & in & 0.2 & Step & 95 & 5 \\
\hline Washing & 4.0 & 2.0 & Step & - & - & - & 100 & out & 0.2 & Ramp & 60 & 40 \\
\hline Loop filling / equilibrating & 6.0 & 2.0 & Step & - & 100 & - & - & in & 0.2 & Ramp & 0 & 100 \\
\hline Washing & 9.0 & 2.0 & Step & - & - & - & 100 & out & 0.2 & Step & 0 & 100 \\
\hline Washing & 11.5 & 2.0 & Step & - & 100 & - & - & out & 0.2 & Ramp & 95 & 5 \\
\hline Equilibrating & 14.0 & 2.0 & Step & - & - & 100 & - & out & 0.2 & Step & 95 & 5 \\
\hline Equilibrating & 18.0 & 2.0 & Step & - & - & 100 & - & out & 0.2 & Step & 95 & 5 \\
\hline
\end{tabular}


Table 3

Retention times, parent ions and accurate mass of the polyphenols examined determined by LC-ESI-Orbitrap ${ }^{\mathrm{TM}}-\mathrm{MS} / \mathrm{MS}$.

\begin{tabular}{lllll}
\hline Compound & $\begin{array}{l}\text { Retention time } \\
\text { (min) }\end{array}$ & $\begin{array}{l}\text { Parent } \\
\text { ion }\end{array}$ & $\begin{array}{l}\text { Molecular } \\
\text { formula }\end{array}$ & $\begin{array}{l}\text { Accurate } \\
\text { mass }\end{array}$ \\
\hline Gallic acid & 10.51 & 169 & $\mathrm{C}_{7} \mathrm{H}_{6} \mathrm{O}_{5}$ & 169.014 \\
Vanillic acid & 11.72 & 167 & $\mathrm{C}_{8} \mathrm{H}_{8} \mathrm{O}_{4}$ & 167.041 \\
Caffeic acid & 11.78 & 179 & $\mathrm{C}_{9} \mathrm{H}_{8} \mathrm{O}_{4}$ & 179.034 \\
Syringic acid & 11.82 & 197 & $\mathrm{C}_{9} \mathrm{H}_{10} \mathrm{O}_{5}$ & 197.045 \\
Chlorogenic & 11.06 & 353 & $\mathrm{C}_{16} \mathrm{H}_{18} \mathrm{O}_{9}$ & 353.087 \\
$\quad$ & & & & \\
$\quad$ acid & 12.45 & 193 & $\mathrm{C}_{10} \mathrm{H}_{10} \mathrm{O}_{4}$ & 193.057 \\
Ferulic acid & 13.55 & 302 & $\mathrm{C}_{14} \mathrm{H}_{6} \mathrm{O}_{8}$ & 302.195 \\
Ellagic acid & 15.37 & 269 & $\mathrm{C}_{15} \mathrm{H}_{10} \mathrm{O}_{5}$ & 271.060 \\
Kaempigenin & 14.29 & 285 & $\mathrm{C}_{15} \mathrm{H}_{10} \mathrm{O}_{6}$ & 285.040 \\
Myricetin & 13.08 & 317 & $\mathrm{C}_{15} \mathrm{H}_{10} \mathrm{O}_{8}$ & 317.037 \\
Naringenin & 14.09 & 272 & $\mathrm{C}_{27} \mathrm{H}_{32} \mathrm{O}_{14}$ & 272.067 \\
Quercetin & 12.79 & 301 & $\mathrm{C}_{21} \mathrm{H}_{20} \mathrm{O}_{11}$ & 447.093 \\
Luteolin & 15.25 & 285 & $\mathrm{C}_{15} \mathrm{H}_{10} \mathrm{O}_{6}$ & 285.040 \\
Pinocembrin & 15.32 & 255 & $\mathrm{C}_{15} \mathrm{H}_{12} \mathrm{O}_{4}$ & 255.073 \\
Hesperidin & 12.80 & 609 & $\mathrm{C}_{16} \mathrm{H}_{14} \mathrm{O}_{6}$ & 609.189 \\
Rutin & 14.36 & 610 & $\mathrm{C}_{27} \mathrm{H}_{30} \mathrm{O}_{16}$ & 610.012 \\
Catechin & 9.37 & 289 & $\mathrm{C}_{15} \mathrm{H}_{14} \mathrm{O}_{6}$ & 289.071 \\
Epicatechin & 9.86 & 289 & $\mathrm{C}_{15} \mathrm{H}_{14} \mathrm{O}_{6}$ & 289.071 \\
\hline
\end{tabular}

Table 4

Linearity values, method detection and quantification limits, applicability range and recovery of the LC-HRMS method developed.

\begin{tabular}{llllll}
\hline Compound & & $\begin{array}{l}\mathrm{LoD} \\
(\mu \mathrm{g} \\
\left.\mathrm{Kg}^{-1}\right)\end{array}$ & $\begin{array}{l}\text { LoQ } \\
(\mu \mathrm{g} \\
\left.\mathrm{Kg}^{-1}\right)\end{array}$ & $\begin{array}{l}\text { Application } \\
\text { range }\left(\mu \mathrm{Kg} \mathrm{Kg}^{-1}\right)\end{array}$ & $\begin{array}{l}\text { Recovery } \\
(\%)\end{array}$ \\
\hline Gallic acid & 0.9987 & 10 & 20 & $20-1000$ & 98 \\
Vanillic acid & 0.9927 & 10 & 20 & $20-1000$ & 95 \\
Caffeic acid & 0.9974 & 10 & 20 & $20-1000$ & 105 \\
Syringic acid & 0.9952 & 10 & 20 & $20-1000$ & 109 \\
Chlorogenic & 0.9990 & 10 & 20 & $20-1000$ & 99 \\
$\quad$ acid & & & & & \\
Ferulic acid & 0.9897 & 10 & 20 & $20-1000$ & 85 \\
Ellagic acid & 0.9910 & 10 & 20 & $20-1000$ & 97 \\
Apigenin & 0.9934 & 10 & 20 & $20-1000$ & 77 \\
Rutin & 0.9991 & 10 & 20 & $20-1000$ & 93 \\
Kaempferol & 0.9991 & 10 & 20 & $20-1000$ & 119 \\
Myricetin & 0.9899 & 10 & 20 & $20-1000$ & 108 \\
Naringenin & 0.9910 & 10 & 20 & $20-1000$ & 100 \\
Quercetin & 0.9889 & 10 & 20 & $20-1000$ & 96 \\
Luteolin & 0.9965 & 10 & 20 & $20-1000$ & 92 \\
Pinocembrin & 0.9959 & 10 & 20 & $20-1000$ & 106 \\
Hesperidin & 0.9969 & 10 & 20 & $20-1000$ & 109 \\
Catechin & 0.9998 & 10 & 20 & $20-1000$ & 71 \\
Epicatechin & 0.9981 & 10 & 20 & $20-1000$ & 75 \\
& & & & &
\end{tabular}

followed by chlorogenic acid $(143.4 \pm 57.6 \mu \mathrm{g} \mathrm{kg}-1)$. The highest caffeic acid contents were found in honey samples from Bisacquino and Palazzo Adriano with maximum values of $789.71 \mu \mathrm{g} \mathrm{kg}-1$ and $664.32 \mu \mathrm{g}$ $\mathrm{kg}^{-1}$, respectively. The honey samples produced by Sicilian black honeybees showed kaempferol $\left(5649.4 \pm 1739.2 \mu \mathrm{g} \mathrm{kg} \mathrm{kg}^{-1}\right)$, quercetin $\left(2909.1 \pm 1990.4 \mu \mathrm{g} \mathrm{kg}^{-1}\right)$, myricetin $\left(131.2 \pm 352.7 \mu \mathrm{g} \mathrm{kg}^{-1}\right)$, pinocembrin $\left(1439.4 \pm 748.3 \mu \mathrm{g} \mathrm{kg} \mathrm{kg}^{-1}\right)$, caffeic $\left(555.9 \pm 97.9 \mu \mathrm{g} \mathrm{kg} \mathrm{kg}^{-1}\right)$ and chlorogenic $\left(184.6 \pm 38.4 \mu \mathrm{g} \mathrm{kg} \mathrm{kg}^{-1}\right)$ acids contents up to two times higher than what was found in honey produced by common honeybees. Our findings on the honey samples produced by Sicilian black honeybee were in contrast to what was reported by Tenore et al. (Tenore et al., 2012) in honey samples from Termini Imerese (Palermo, Southern Italy), which revealed higher hydroxybenzoic (gallic, vanillic and syringic acids) acids contents than flavonols, in accordance with other works reported previously on Apis mellifera ssp. Ligustica honey samples (Hadj et al., 2014; Biesaga and Pyrzynska, 2009; Sergiel et al., 2014). These differences could be attributed to the environmental and botanical differences of the sampling areas. Unfortunately, the melissopalynology results did not allow us to have a comparison between the two studies based on the botanical origin of the honey samples. Among the flavonols group, the kaempferol contents found in the present work were higher than what was reported by Sergiel et al. (Sergiel et al., 2014) in honey samples from western Poland. On the contrary, the quercetin contents were lower than those reported by Sergiel et al. (Sergiel et al., 2014) but higher than those found by Biesaga and Pyrzynska (Biesaga and Pyrzynska, 2009). All the hydroxybenzoic (Gallic acid, vanillic acid and syringic acid) and hydroxycinnamic (caffeic acid, chlorogenic acid and ferulic acid) acids contents found in this work were lower than what was reported in previous works (Hadj et al., 2014; Biesaga and Pyrzynska, 2009; Sergiel et al., 2014). Our findings on naringenin contents were comparable to those observed by Biesaga and Pyrzynska (Biesaga and Pyrzynska, 2009).

\subsection{Multivariate analysis}

Given the high number of polyphenols as variables, Principal Component Analysis (PCA) was used to explore the dataset structure and to obtain more information on the variables that mainly influence samples similarities and differences.

The PCA model calculated on the autoscaled data (105 samples and 14 variables) showed that the information sought was clearly visible in the first two principal components, accounting for $58.3 \%$ of total data variance. The PC1 vs. PC2 score plot reporting the honey samples colored by honeybee subspecies is shown in Fig. 1: a clear separation of samples into two groups was found according to the two subspecies. The samples from Apis mellifera ssp. Ligustica lie mainly at negative values of both PC1 and PC2, while those from Apis mellifera ssp. Sicula are mainly found at positive values of the two PCs. A more detailed inspection of the sub-clusters of the two groups showed that they essentially correspond to the different sampling sites. For example, the sub-cluster located at the higher values of PC2 corresponds to all the samples from Contessa Entellina, while the samples lying at the higher values of PC1 and at PC2 values approximately equal to -1 were those from Agrigento.

The loading plot of PC1 vs. PC2 describing the variables which characterise the two groups is shown in Fig. 2. All the variables are approximately equidistant from the origin, therefore they all contribute in a similar way to the first two principal components (i.e., they are all informative). The Apis mellifera ssp. Ligustica honey samples, which are found at the bottom left in the score plot, generally show a higher content of rutin (lower left in loading plot) than Apis mellifera ssp. Sicula honey samples. Conversely, the Apis mellifera ssp. Sicula honey samples show higher contents of hydroxybenzoic acids, hydroxycinnamic acids and hesperidin. Therefore, the overall polyphenols profile allows to distinguish honey samples produced by black honeybees from those by common honeybees.

Fig. 3 reports the same PC1 vs. PC2score plot of Fig. 1, but in this case the samples are represented with different colors according to the sampling areas. Two groups are clearly distinguished for Palermo and Agrigento provinces, respectively. Considering that the separation between the two groups is along PC2 it should be noted that, compared to the samples from Agrigento province, on the whole the samples from Palermo province show higher values of syringic acid and hesperidin, and lower values of rutin. Furthermore, it can be observed that the samples from Agrigento province are much more dispersed along PC1 than those from Palermo province. This fact can be ascribed to the greater variability of the content of kaempferol, chlorogenic acid, pinocembrin, quercetin and naringenin within the samples from Agrigento province with respect to those from Palermo province.

\section{Conclusion}

A rapid, cheap, and reliable LC-ESI-Orbitrap ${ }^{\mathrm{TM}}$-MS method was carried out according to the procedure outlined in EN ISO/IEC 17025:2005 ("ISO/IEC 17025:2005 - General requirements for the competence of testing 
Table 5

Polyphenols average values (expressed in $\mu \mathrm{kg}^{-1}$ ) of the honey samples examined according to the sampling site. n.d. $=$ not detected.

\begin{tabular}{|c|c|c|c|c|c|c|c|c|c|c|c|c|}
\hline & Bisacquino & $\begin{array}{l}\text { Contessa } \\
\text { Entellina }\end{array}$ & $\begin{array}{l}\text { Palazzo } \\
\text { Adriano }\end{array}$ & Lercara Friddi & Agrigento & Raffadali & $\begin{array}{l}\text { S. Biagio } \\
\text { Platani }\end{array}$ & Sciacca & Ribera & Racalmuto & Licata & Naro \\
\hline $\begin{array}{l}\text { Apigenin(mean } \pm \text { sd) } \\
\text { Luteolin }(\text { mean } \pm \text { sd) }\end{array}$ & $\begin{array}{l}497.3 \pm 63.11 \\
\text { n.d. }\end{array}$ & $\begin{array}{l}322.6 \pm 40.07 \\
\text { n.d. }\end{array}$ & $\begin{array}{l}203.8 \pm 36.56 \\
\text { n.d. }\end{array}$ & $\begin{array}{l}175.5 \pm 25.89 \\
\text { n.d. }\end{array}$ & $\begin{array}{l}1254 \pm 132.6 \\
\text { n.d. }\end{array}$ & $\begin{array}{l}74.56 \pm 9.69 \\
\text { n.d. }\end{array}$ & $\begin{array}{l}227.4 \pm 37.64 \\
\text { n.d. }\end{array}$ & $\begin{array}{l}1269 \pm 133.7 \\
\text { n.d. }\end{array}$ & $\begin{array}{l}957.9 \pm 101.6 \\
\text { n.d. }\end{array}$ & $\begin{array}{l}378.7 \pm 42.78 \\
\text { n.d. }\end{array}$ & $\begin{array}{l}1236 \pm 131.3 \\
\text { n.d. }\end{array}$ & $\begin{array}{l}420.9 \pm 57.32 \\
\text { n.d. }\end{array}$ \\
\hline Kaempferol (mean \pm sd) & $4585 \pm 621.0$ & $4935 \pm 653.8$ & $3966 \pm 551.2$ & $2391 \pm 334.7$ & $7744 \pm 1084$ & $1119 \pm 156.6$ & $2041 \pm 285.7$ & $2177 \pm 304.8$ & $3471 \pm 485.9$ & $7545 \pm 1056$ & $2480 \pm 347.3$ & $3719 \pm 520.6$ \\
\hline Quercetin(mean \pm sd) & $1376 \pm 233.9$ & $1465 \pm 249.0$ & $4822 \pm 675.1$ & $2987 \pm 507.8$ & $5089 \pm 712.5$ & $1780 \pm 302.6$ & $1249 \pm 212.3$ & $1206 \pm 205.0$ & $1512 \pm 257.0$ & $7184 \pm 1221$ & $3890 \pm 661.3$ & $1248 \pm 212.2$ \\
\hline Rutin(mean \pm sd) & n.d. & $20.14 \pm 4.03$ & n.d. & n.d. & n.d. & n.d. & $45.72 \pm 9.14$ & $46.96 \pm 9.40$ & $89.51 \pm 17.90$ & $71.02 \pm 14.20$ & $102.6 \pm 20.52$ & $73.90 \pm 14.80$ \\
\hline Myricetin(mean $\pm s d)$ & $56.01 \pm 7.28$ & $43.83 \pm 5.70$ & $77.28 \pm 10.04$ & $98.26 \pm 12.77$ & $94.33 \pm 12.26$ & $41.49 \pm 5.39$ & $42.27 \pm 5.50$ & $42.14 \pm 5.48$ & $39.24 \pm 5.10$ & $1871 \pm 243.2$ & $989.0 \pm 128.6$ & $42.70 \pm 5.55$ \\
\hline Hesperidin (mean $\pm s d)$ & $21.44 \pm 3.22$ & $70.91 \pm 10.64$ & $41.47 \pm 6.22$ & $20.09 \pm 3.01$ & $36.97 \pm 5.54$ & n.d. & $32.39 \pm 4.86$ & $26.05 \pm 3.91$ & $50.92 \pm 7.64$ & n.d. & n.d. & $28.13 \pm 4.22$ \\
\hline Naringenin (mean \pm sd) & $92.53 \pm 10.17$ & $86.02 \pm 9.46$ & $105.2 \pm 11.57$ & $100.8 \pm 11.08$ & $170.2 \pm 18.72$ & $30.84 \pm 3.39$ & $49.95 \pm 5.49$ & $40.51 \pm 4.46$ & $73.25 \pm 8.06$ & $103.2 \pm 11.35$ & $40.04 \pm 4.40$ & $258.1 \pm 28.40$ \\
\hline $\begin{array}{l}\text { Pinocembrin } \\
\quad(\text { mean } \pm \text { sd })\end{array}$ & $961.6 \pm 144.2$ & $924.5 \pm 138.7$ & $1286 \pm 193.0$ & $636.5 \pm 95.50$ & $2564 \pm 384.6$ & $359.3 \pm 53.90$ & $735.5 \pm 110.3$ & $924.7 \pm 138.7$ & $1343 \pm 201.5$ & $1549 \pm 232.3$ & $764.2 \pm 114.6$ & $1343 \pm 201.4$ \\
\hline Caffeic acid (mean \pm sd) & $658.1 \pm 46.07$ & $553.6 \pm 38.75$ & $513.0 \pm 35.91$ & $376.4 \pm 26.35$ & $493.8 \pm 34.57$ & $223.0 \pm 15.61$ & $211.0 \pm 14.77$ & $173.1 \pm 12.12$ & $401.2 \pm 28.08$ & $416.2 \pm 29.13$ & $168.1 \pm 11.77$ & $281.7 \pm 19.72$ \\
\hline $\begin{array}{l}\text { Chlorogenic acid } \\
\quad(\text { mean } \pm \text { sd })\end{array}$ & $170.9 \pm 20.51$ & $157.5 \pm 18.90$ & $221.0 \pm 26.52$ & $174.9 \pm 21.00$ & $215.6 \pm 25.87$ & $50.88 \pm 6.10$ & $113.3 \pm 13.60$ & $45.40 \pm$ & $100.4 \pm 12.05$ & $234.1 \pm 28.09$ & $159.5 \pm 19.14$ & $73.72 \pm 8.85$ \\
\hline Ellagic acid (mean \pm sd) & n.d. & n.d. & n.d. & n.d. & n.d. & n.d. & n.d. & n.d. & n.d. & n.d. & n.d. & n.d. \\
\hline Ferulic acid (mean \pm sd) & $50.96 \pm 6.70$ & $39.06 \pm 5.47$ & $59.38 \pm 5.47$ & $45.31 \pm 5.47$ & $76.78 \pm 10.75$ & $23.56 \pm 3.30$ & $59.69 \pm 8.36$ & $50.23 \pm 7.03$ & $48.92 \pm 6.85$ & $66.38 \pm 9.30$ & $40.59 \pm 5.68$ & $60.04 \pm 8.40$ \\
\hline Gallic acid (mean $\pm \mathrm{sd}$ ) & n.d. & n.d. & $201.66 \pm 26.21$ & $125.5 \pm 16.31$ & n.d. & n.d. & n.d. & n.d. & n.d. & $85.66 \pm 11.13$ & $334.2 \pm 43.45$ & n.d. \\
\hline $\begin{array}{l}\text { Syringic acid } \\
\quad(\text { mean } \pm \text { sd })\end{array}$ & n.d. & $374.0 \pm$ & n.d. & n.d. & $32.74 \pm$ & n.d. & n.d. & n.d. & n.d. & n.d. & n.d. & n.d. \\
\hline Vanillic acid (mean \pm sd) & $358.5 \pm 43.02$ & $108.6 \pm 13.03$ & $271.0 \pm 32.52$ & $174.2 \pm 20.90$ & $176.1 \pm 21.13$ & $93.41 \pm 11.21$ & $48.04 \pm 5.76$ & $74.57 \pm 8.95$ & $91.45 \pm 10.97$ & $230.0 \pm 27.60$ & $118.7 \pm 14.24$ & $118.6 \pm 14.23$ \\
\hline Catechin (mean \pm sd) & n.d. & n.d. & n.d. & n.d. & n.d. & n.d. & n.d. & n.d. & n.d. & n.d. & n.d. & n.d. \\
\hline Epicatechin (mean \pm sd) & n.d. & n.d. & n.d. & n.d. & n.d. & n.d. & n.d. & n.d. & n.d. & n.d. & n.d. & n.d. \\
\hline
\end{tabular}


Table 6

Mean \pm SD polyphenols values (expressed in $\mu \mathrm{g} \mathrm{kg}^{-1}$ ) of the honey samples examined according to the honeybee subspecies. n.d. $=$ not detected.

\begin{tabular}{|c|c|c|c|}
\hline & $\begin{array}{l}\text { Apis mellifera ssp. } \\
\text { Ligustica }(\mathrm{N}=51)\end{array}$ & $\begin{array}{l}\text { Apis mellifera ssp. } \\
\text { Sicula }(\mathrm{N}=54)\end{array}$ & Total $(\mathrm{N}=105)$ \\
\hline Apigenin & $444.8 \pm 436.6$ & $619.7 \pm 418.5$ & $534.8 \pm 434.3$ \\
\hline Luteolin & n.d. & n.d. & n.d. \\
\hline Kaempferol & $2187.5 \pm 655.3$ & $5649.4 \pm 1739.2$ & $3967.9 \pm 2184.16$ \\
\hline Quercetin & $1461.7 \pm 691.2$ & $2909.1 \pm 1990.4$ & $2206.1 \pm 1666.4$ \\
\hline Rutin & $47.9 \pm 19.8$ & $19.8 \pm 10.9$ & $33.5 \pm 21.2$ \\
\hline Myricetin & $82.6 \pm 189.7$ & $131.2 \pm 352.7$ & $107.6 \pm 285.12$ \\
\hline Hesperidin & $29.1 \pm 7.2$ & $44.5 \pm 21.9$ & $36.9 \pm 18.2$ \\
\hline Naringenin & $66.4 \pm 60.3$ & $113.1 \pm 41.4$ & $90.4 \pm 56.3$ \\
\hline Pinocembrin & $790.6 \pm 256.3$ & $1439.4 \pm 748.3$ & $1124.3 \pm 650.5$ \\
\hline Caffeic acid & $223.3 \pm 62.9$ & $555.9 \pm 97.9$ & $394.1 \pm 186.3$ \\
\hline $\begin{array}{l}\text { Chlorogenic } \\
\text { acid }\end{array}$ & $99.8 \pm 39.6$ & $184.6 \pm 38.4$ & $143.4 \pm 57.6$ \\
\hline Ellagic acid & n.d. & n.d. & n.d. \\
\hline Ferulic acid & $53.6 \pm 12.9$ & $55.1 \pm 17.4$ & $54.4 \pm 15.3$ \\
\hline Gallic acid & $24.9 \pm 70.7$ & $22.9 \pm 53.9$ & $23.9 \pm 62.4$ \\
\hline Syringic acid & $5.2 \pm 0.8$ & $144.3 \pm 173$ & $76.7 \pm 141.9$ \\
\hline Vanillic acid & $72.4 \pm 37.8$ & $208.7 \pm 106.4$ & $142.5 \pm 105.6$ \\
\hline Catechin & n.d. & n.d. & n.d. \\
\hline Epicatechin & n.d. & n.d. & n.d. \\
\hline
\end{tabular}

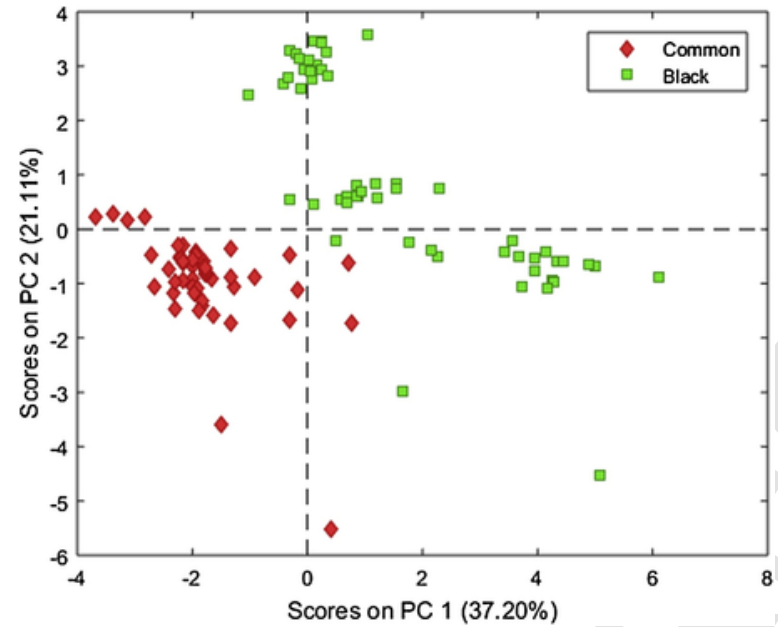

Fig. 1. PC1vs.PC2score plot of polyphenols content of the honey samples, according to the honeybee subspecies. Black = Apis mellifera ssp. Sicula honey samples; Common = Apis mellifera ssp. Ligustica.

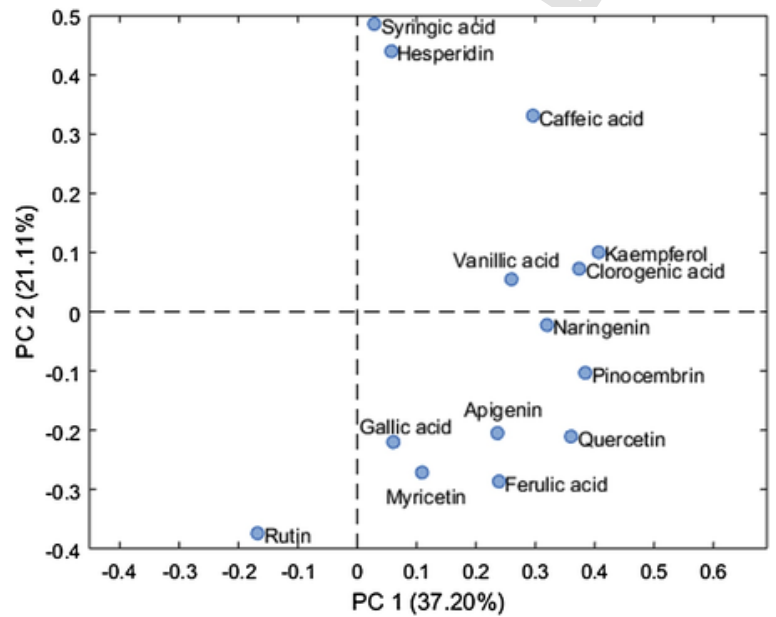

Fig. 2. PCA loading plot (PC1vs.PC2) of polyphenols of the honey samples examined.

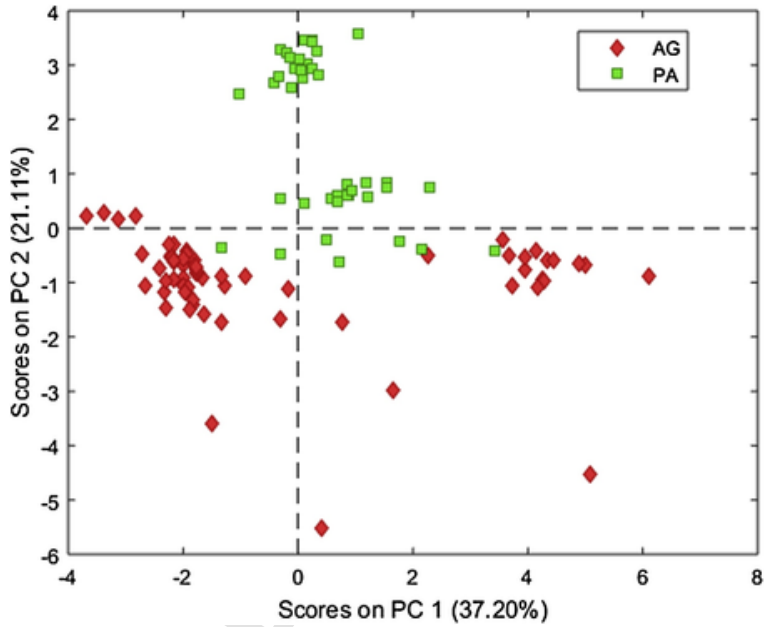

Fig. 3. PC1vs.PC2 score plot of polyphenols content of the honey samples, according to the sampling macro-areas. AG = honey samples from Agrigento province; $\mathrm{PA}=$ honey samples from Palermo province.

calibration laboratories," n.d.). The proposed method allowed for the analysis of a large number of samples in less than $20 \mathrm{~min}$, including extraction, purification, and determination. Furthermore, the method was used to determine the exact mass of each analyte. The majority of polyphenols contents were found in honey samples produced by Sicilian black honeybees rather than those by common honeybees. Very high levels of kaempferol and quercetin were found in the honey from Sicilian black honeybees. The Principal Component Analysis of polyphenols content showed a clear separation between the honey samples, both according to the honeybee subspecies and to the production area. Therefore, these results suggest that polyphenols content determination can be considered as an effective tool for traceability of Sicilian honey samples. Similarly, this methodology could also be extended to other PDO honeys; the separation between the honey samples highlighted by PCA suggests in fact the possibility of developing efficient classification models based on the content of polyphenols.

\section{Conflict of interest}

The authors declare that they have no conflicts of interest related to the publication of this manuscript.

\section{Acknowledgement}

The authors would like to thank Barbara Randisi from the Istituto Zooprofilattico Sperimentale della Sicilia "A. Mirri" in Palermo, Italy, for the technical support.

\section{References}

Hadj, Badjah, Ahmed, A.Y., Obbed, M.S., Wabaidur, S.M., AlOthman, Z.A., Al-Shaalan, N.H., 2014. High-performance liquid chromatography analysis of phenolic acid, flavonoid, and phenol contents in various natural yemeni honeys using multi-walled carbon nanotubes as a solid-phase extraction adsorbent. J. Agric. Food Chem. 62, 5443-5450. https://doi.org/10.1021/jf5011758.

Ban, J.Y., Nguyen, H.T.T., Lee, H.-J., Cho, S.O., Ju, H.S., Kim, J.Y., Bae, K., Song, K.-S., Seong, Y.H., 2008. Neuroprotective properties of gallic acid from Sanguisorbae Radix on amyloid $\beta$ protein (25-35)-Induced toxicity in cultured rat cortical neurons. Biol. Pharm. Bull. 31, 149-153. https://doi.org/10.1248/bpb.31.149.

Biesaga, M., Pyrzynska, K., 2009. Liquid chromatography/tandem mass spectrometry studies of the phenolic compounds in honey. J. Chromatogr. A 1216, 6620-6626. https:// doi.org/10.1016/j.chroma.2009.07.066.

Bogdanov, S., Jurendic, T., Sieber, R., Gallmann, P., 2008. Honey for nutrition and health: a review. J. Am. Coll. Nutr. 27, 677-689. https://doi.org/10.1080/07315724.2008. 10719745.

Cicero, N., Naccari, C., Cammilleri, G., Giangrosso, G., Cicero, A., Gervasi, T., Tropea, A. Albergamo, A., Ferrantelli, V., 2017. Monitoring of neonicotinoid pesticides in beekeeping. Nat. Prod. Res. 31, 1258-1262. https://doi.org/10.1080/14786419.2016. 1236101.

Filomeni, G., Graziani, I., De Zio, D., Dini, L., Centonze, D., Rotilio, G., Ciriolo, M.R., 2012. Neuroprotection of kaempferol by autophagy in models of rotenone-medi- 
ity: possible implications for Parkinson's disease. Neurobiol. Aging 33, 767-785. https:// doi.org/10.1016/j.neurobiolaging.2010.05.021.

Gheldof, N., Wang, X.-H., Engeseth, N.J., 2002. Identification and quantification of antioxidant components of honeys from various floral sources. J. Agric. Food Chem. 50, 5870-5877. https://doi.org/10.1021/jf0256135.

Helsel, D.R., 2005. Nondetects and data analysis. Statistics for censored environmental data. Nondetects Data Anal. Stat. Censored Environ. Data.

ISO/IEC 17025:2005, General requirements for the competence of testing and calibration laboratories [WWW Document], n.d. URL https://www.iso.org/standard/39883. html (Accessed 10 March 2018).

Kallithraka, S., Arvanitoyannis, I.S., Kefalas, P., El-Zajouli, A., Soufleros, E., Psarra, E., 2001. Instrumental and sensory analysis of Greek wines; implementation of principal component analysis (PCA) for classification according to geographical origin. Food Chem. 73, 501-514. https://doi.org/10.1016/S0308-8146(00)00327-7.

Li, S., Pu, X.-P., 2011. Neuroprotective effect of kaempferol against a 1-Methyl-4-phenyl-1,2,3,6-tetrahydropyridine-Induced mouse model of parkinson's disease. Biol. Pharm. Bull. 34, 1291-1296. https://doi.org/10.1248/bpb.34.1291.

Lo Dico, G.M., Galvano, F., Dugo, G., D'ascenzi, C., Macaluso, A., Vella, A., Giangrosso, G., Cammilleri, G., Ferrantelli, V., 2018. Toxic metal levels in cocoa powder and chocolate by ICP-MS method after microwave-assisted digestion. Food Chem. 245, 1163-1168. https://doi.org/10.1016/j.foodchem.2017.11.052.

López-Gutiérrez, N., Aguilera-Luiz, M., del, M., Romero-González, R., Vidal, J.L.M., Garrido Frenich, A., 2014. Fast analysis of polyphenols in royal jelly products using automated TurboFlow ${ }^{\mathrm{TM}}$-liquid chromatography-Orbitrap high resolution mass spectrometry. J. Chromatogr. B 973, 17-28. https://doi.org/10.1016/j.jchromb.2014.09.038.

Luo, Y., Zhao, H.P., Zhang, J., Wang, J., Yang, W.L., Yang, M., Liao, Z.G., 2012. [Effect of ferulic acid on learning and memory impairments of vascular dementia rats and its mechanism of action]. Yao Xue Xue Bao 47, 256-260.

Mallamace, D., Corsaro, C., Salvo, A., Cicero, N., Macaluso, A., Giangrosso, G., Ferrantelli, V., Dugo, G., 2014. A multivariate statistical analysis coming from the NMR metabolic profile of cherry tomatoes (the Sicilian Pachino case). Phys. Stat. Mech. Its Appl. 401, 112-117. https://doi.org/10.1016/j.physa.2013.12.054.

Mandel, S.A., Avramovich-Tirosh, Y., Reznichenko, L., Zheng, H., Weinreb, O., Amit, T., Youdim, M.B.H., 2005. Multifunctional activities of green tea catechins in neuroprotection. Neurosignals 14, 46-60. https://doi.org/10.1159/000085385.

Ohe, W.V.D., Oddo, L.P., Piana, M.L., Morlot, M., Martin, P., 2004. Harmonized methods of melissopalynology. Apidologie 35, S18-S25. https://doi.org/10.1051/apido: 2004050.

Pantano, L., Cascio, G.L., Alongi, A., Cammilleri, G., Vella, A., Macaluso, A., Cicero, N., Migliazzo, A., Ferrantelli, V., 2016. Fatty acids determination in Bronte pistachios by gas chromatographic method. Nat. Prod. Res. 30, 2378-2382. https://doi.org/10. 1080/14786419.2016.1180599.
Pérez-Gregorio, M.R., Regueiro, J., Simal-Gándara, J., Rodrigues, A.S., Almeida, D.P.F., 2014. Increasing the added-value of onions as a source of antioxidant flavonoids: a critical review. Crit. Rev. Food Sci. Nutr. 54, 1050-1062. https://doi.org/10.1080/ 10408398.2011.624283.

Perez-Gregorio, R., Simal-Gandara, J., 2017. A critical review of bioactive food components, and of their functional mechanisms. Biological Effects and Health Outcomes https://doi.org/10.2174/1381612823666170317122913.

Quifer-Rada, P., Vallverdú-Queralt, A., Martínez-Huélamo, M., Chiva-Blanch, G., Jáuregui, O., Estruch, R., Lamuela-Raventós, R., 2015. A comprehensive characterisation of beer polyphenols by high resolution mass spectrometry (LC-ESI-LTQ-Orbitrap-MS). Food Chem. 169, 336-343. https://doi.org/10.1016/j.foodchem.2014.07.154.

Ricciardelli D'Albore, 1998. Mediterranean Melissopalynology [WWW Document]. URL http://www.izsum.it/Melissopalynology/.

Rodríguez-Delgado, , González-Hernández, G., Conde-González, J.-E., Pérez-Trujillo, J.-P., 2002. Principal component analysis of the polyphenol content in young red wines. Food Chem. 78, 523-532. https://doi.org/10.1016/S0308-8146(02)00206-6.

Ruttner, F., 2013. Biogeography and Taxonomy of Honeybees. Springer Science \& Business Media.

Seeram, N.P., Adams, L.S., Henning, S.M., Niu, Y., Zhang, Y., Nair, M.G., Heber, D., 2005 In vitro antiproliferative, apoptotic and antioxidant activities of punicalagin, ellagic acid and a total pomegranate tannin extract are enhanced in combination with other polyphenols as found in pomegranate juice. J. Nutr. Biochem. 16, 360-367. https:// doi.org/10.1016/j.jnutbio.2005.01.006.

Sergiel, I., Pohl, P., Biesaga, M., 2014. Characterisation of honeys according to their content of phenolic compounds using high performance liquid chromatography/tandem mass spectrometry. Food Chem. 145, 404-408. https://doi.org/10.1016/j.foodchem. 2013.08.068.

Tenore, G.C., Ritieni, A., Campiglia, P., Novellino, E., 2012. Nutraceutical potential of monofloral honeys produced by the Sicilian black honeybees (Apis mellifera ssp. sic ula). Food Chem. Toxicol. 50, 1955-1961. https://doi.org/10.1016/j.fct.2012.03.067.

Uzar, E, Alp, H., Cevik, M.U., Firat, U., Evliyaoglu, O., Tufek, A., Altun, Y., 2012. Ellagic acid attenuates oxidative stress on brain and sciatic nerve and improves histopathology of brain in streptozotocin-induced diabetic rats. Neurol. Sci. 33, 567-574. https: //doi.org/10.1007/s10072-011-0775-1.

Vallverdú-Queralt, A., Boix, N., Piqué, E., Gómez-Catalan, J., Medina-Remon, A., Sasot, G., Mercader-Martí, M., Llobet, J.M., Lamuela-Raventos, R.M., 2015. Identification of phenolic compounds in red wine extract samples and zebrafish embryos by HPLC-ESI-LTQ-Orbitrap-MS. Food Chem. 181, 146-151. https://doi.org/10.1016/j. foodchem.2015.02.098 